\title{
Gold standard: a failed concept
}

\author{
Peter E. Petros ${ }^{1}$
}

Received: 1 June 2015 / Accepted: 2 August 2015 / Published online: 21 August 2015

(C) The International Urogynecological Association 2015

Keywords TVT · Gold standard

\section{Dear Editor,}

I fully support the Editorial describing the gold standard as a failed concept [1]. As one of the culprits [2], a short explanation is in order. The title of the 2014 Lecture [2] was actually cast upon us. It was a shorthand way to describe the thrust of the lecture, how the tension-free vaginal tape (TVT) originated (Petros) and was propagated (Nilsson). Actually, nothing was more odious to Ulmsten and I, while we were struggling to legitimise the midurethral sling, than to read descriptions about the "gold standard" Burch. This phrase still rankles, especially when applied to the TVT.

Who decides what is a "gold standard"? Who is so omniscient and wise as to be able to make such a statement? "Gold standard" implies perfection. It discourages innovation.

It contravenes all Popper's precepts [3], that nothing can be finally proven. There is always something that supersedes a known theory or practice: Ptolemaic astronomy by Copernican, Burch by TVT.

Does this mean that the TVT method cannot be the final technique? Certainly. Already "minislings" have appeared, but they are not fundamentally different, as they apply the same anatomy but less invasively. Could there be more fundamental changes? My view is "yes".

Peter E. Petros

pp@kvinno.com

1 Professorial Surgery Unit, St Vincent's Hospital, University of NSW, Darlinghurst Road, Darlinghurst Sydney, NSW 2010, Australia
The TVT works by creating an artificial collagenous neoligament that reinforces the natural pubourethral ligament (PUL). The PUL contains collagen, smooth muscles, elastin, nerves, blood vessels; thus, the ligament contracts during effort and relaxes during micturition, a finely tuned, neurologically controlled mechanism. In contrast, the TVT neoligament principle provides a solid non-contractile collagen strut. This explains why it is not possible to achieve $100 \%$ dryness in all circumstances. Fine tuning is not possible. Stem cell treatment offers the prospect of regenerating all the elements of the ligament so it can "fine tune".

The word "standard" is also problematical. For example, the standard metre is the distance between two marks on 90 $\%$ platinum $/ 10 \%$ iridium alloy bar kept in Paris. At least in the English system of law, "standard" is the equivalent of the French metre bar; any deviation can leapt upon by our legal friends. Maybe Popper's concept of a fluid ever evolving science is best.

Or as the editorial says, "Instead of blindly following a gold standard, let us look at the evidence ourselves and apply it critically in a specific healthcare setting to the individual patient. Isn't this what evidence-based medicine is all about?"

Conflict of Interest None.

\section{References}

1. Ralph G, Aigmueller T, Riss P (2015) The failed idea of a gold standard. Int Urogynecol J. doi:10.1007/s00192-015-2729-2

2. Petros P (2015) Creating a gold standard surgical device: scientific discoveries leading to TVT and beyond. Int Urogynecol J 26:471-476

3. Popper KR (1980) The logic of scientific discovery. Unwin, Hyman, London, pp 27-146 